\title{
NEWS, VIEWS AND COMMENTS
}

\section{College-Age Twins: University Admission Policies /} Twin Research: Birth Weight and Neuromotor Performance; Transfusion Syndrome Markers; Vanishing Twins and Fetal Sex Determination; MZ Twin Discordance for Wilson's Disease / Media: Big at Birth; Planned Separation of Conjoined Twins; X Factor Twins; Cinema: The Identical

\author{
Nancy L. Segal \\ Department of Psychology, California State University, Fullerton, CA, USA
}

There is a lack of research findings addressing the unique college admissions issues faced by twins and other multiples. The advantages and disadvantage twins face, as reported by college administrators, twins and families are reviewed. Next, recent research addressing twins' birth weight and neuromotor performance, transfusion syndrome markers, the vanishing twin syndrome and monozygotic (MZ) twin discordance for Wilson's disease is described. News items concerning the birth of unusually large twins, the planned separation of conjoined twins, twin participants in the X Factor games and a film, The Identical, are also summarized.

\section{College-Age Twins: University Admissions Policies}

Every fall, thousands of pairs of high school twins around the world face vexing choices, over and beyond those of non-twins. Their concerns not only include (1) identifying colleges best suited to their interests and talents, but also (2) deciding if it is in their best interests to attend the same college as their twin, and (3) determining if applying to the same school(s) as their twin would help or hinder their chances for acceptance. High school counselors and other school administrators are well versed in matching candidates to colleges. Unfortunately, there is no available systematic research addressing the advantages and disadvantages of twins' applying to the same or separate schools. Furthermore, little is known about the factors behind their decision-making processes and the short- and long-term consequences of their college choices. However, there is anecdotal evidence pertaining to these issues from some college admissions officers and from twins and families in the United States. A web site, Twiniversity, contains a detailed essay from a mother of twins, documenting her daughters' college admissions experiences (Lyons, 2014). A review of this material will, hopefully, encourage study of a neglected, yet extremely important area of concern.

ADDRESS FOR CORRESPONDENCE: Nancy L. Segal, Department of Psychology, California State University, Fullerton, CA 92834, USA.E-mail: nsegal@fullerton.edu 
An interview with an unnamed college dean highlights several key issues surrounding twins' college applications (Rubenstone, 2014). The comment was in response to a question posed by a twin who was a high school covaledictorian along with her twin sister. The twins' question was whether or not both should apply to Harvard - specifically, would their 'standing out' as twins help them by drawing attention, or hurt them if the admissions committee could not decide between them and rejected both. Another strategy they considered was having one twin apply to Harvard and the other twin apply to Yale, both on early admission. They reasoned that if one or both were accepted at these schools, then the other could apply to her twin sister's school on regular admissions, offering the option to stay together or to separate.

The dean responding to these concerns favored the second strategy, saying that applying to separate colleges increases the likelihood of twins' acceptance, and that if one twin was accepted early, the committee would find it difficult to reject the other. While most schools do not maintain official policies on twins and insist that they view applications individually, this may not necessarily be the case. For example, representatives from the University of Maryland, the University of Texas, Rice University and the Massachusetts Institute of Technology (MIT) agree that applications are reviewed individually. These same representatives also say that the schools try to accept or reject both twins. In fact, one admissions expert who works independently of any university claims that schools often consider twins as a unit (Kaplan, 2008). This sounds as though being a twin would benefit college admission. However, it is important to emphasize that these comments are based on impressions, not on carefully gathered data. It is also the case that schools may not always know which applicants are one of a pair.

Interestingly, Duke University is one of a few universities to request that applicants indicate if he or she is a twin (Mosle, 2008). They have implemented this practice for two reasons. The first is that if the twins' names and/or email addresses are similar then materials (e.g., letters of recommendation) intended for one twin might be inadvertently placed in the file of the other twin. A second reason poses some concern. Specifically, selective institutions are adept at magnifying small differences between candidates, so a minor twin difference might seem more significant than it really is, causing one co-twin to be rejected. A father of twins was perplexed when one of his identical twin children was rejected from an elite college that had accepted the cotwin; he insisted that his children were very much alike in every way. The undergraduate dean responding to this father's concern was forced to consider the extent to which the co-twin difference on which the admissions committee had acted was truly meaningful. It is well known that people tend to magnify small differences between twins, especially identical twins.

This same dean appreciated that twins and triplets can be very much alike. He also noted that, 'It's interesting when they're not similar at all, and we might wonder why that's the case' (Mosle, 2008). The answer is that not all twins are $\mathrm{MZ}$; dizygotic (DZ) twins might be similar in overall academic standing, but show very different abilities. DZ twins can also differ in their academic talents and interests, due to their genetic differences. Of course, DZ twins who show marked academic differences are unlikely to apply to the same schools. Hopefully, most school administrators are aware of the different twin types and the reasons why co-twins and co-triplets may be similar or different.

It is helpful to consider the college admission process of DZ triplets composed of two females and one male (Mosle, 2008). One of the females was eager for admission to Harvard as a member of its debating team. However, she applied to Yale instead, even though this meant giving up debating. She worried that her brother might be denied admission to Harvard if she applied, given that several students from her high school were applying to Harvard and it was unlikely that more than two would be accepted. It turned out that her brother was accepted, and felt bothered by the fact that his sister had withdrawn her application without consulting him. This underlines the fact that twins might limit their options when it may not be necessary.

The experience of MZ/DZ female triplets is also illuminating. The high school seniors chose different colleges; the DZ co-triplet wished to be viewed as an individual, not as one third of a set. However, she was unhappy at college and transferred the following semester to the same school as one of her sisters. The sister who was there initially had won a prestigious Danforth Fellowship, an honor also won by the newcomer, causing some resentment.

Given the foregoing, the key issues for future research appear to be: (1) determining the college admissions policies for twins at a range of representative institutions, (2) obtaining accurate statistics on the college admission and rejection rates of twins, with respect to zygosity and gender, (3) obtaining statistics on the number of twins who attend similar and separate colleges, and learning if and how these choices change during their college careers, and (4) understanding the processes guiding twins' decisions as to where to apply and where to go.

Some twins prefer to be together, others do not. A possible compromise is to attend the same school, but live in separate dormitories or apartments. Most importantly, there is no single solution that will apply to all twins. 


\section{Twin Research}

\section{Birth Weight and Neuromotor Performance}

Researchers in Portugal examined associations between low birth weight and neuromotor performance (Lopes et al., 2014). The sample included 191 children from 83 twin pairs, 7 triplet sets, and 1 quadruplet set. The number of MZ and DZ pairs was not provided, although 78 children belonged to $\mathrm{MZ}$ pairs and 113 children belonged to $\mathrm{DZ}$ pairs. The age of the children ranged from 5 to 17 years, and zygosity was assessed by analysis of 17 short tandem repeat markers. Twins completed the Zurich Neuromotor Assessment that includes tests for five relevant measures: repetitive movements, alternating movements, diadochokinesis (sequential movements), pegboard (dynamic balance), and static balance (stress gaits). All movements were video recorded for analysis. Birth weight explained $11 \%$ of the variance in neuromotor performance across zygosity groups. Between $32.7-76.9 \%$ of the children were below the 10th percentile for timed tasks (e.g., dynamic and static balance), although fewer than $6.4 \%$ of the children were below the 10th percentile for associated movements. Genetic influence was found for purely motor tasks, adaptive fine motor tasks and dynamic balance, but not for static balance or associated movements.

The generally poor performance of the twins is of concern. Their average birth weight was 2,246.3 $( \pm 485)$ grams or $4.94( \pm 1.07)$ pounds. While birth weight did not contribute substantially to the twins' performance, extremely low birth weights have been linked to poor neuromotor performance in non-twins. Therefore, it will be important to identify the source of the twins' performance on the different tasks.

\section{Vanishing Twins and Fetal Sex Determination}

Fetal sex determination is an important procedure when infants are at risk for sex-linked conditions. Fetal DNA found in maternal plasma can be examined for the presence of a $Y$ chromosome: a $Y$ chromosome indicates a male, while the absence of a Y chromosome indicates a female. The possibility that inaccurate diagnoses of fetal sex indicate a vanishing twin was raised in a recent case report (Vlková \& Hodosy, 2014). At 10 weeks gestation, the fetus carried by a healthy 24 -year-old woman appeared to be male, with a very high degree of certainty, across several parameters (95.4-98.9\%). However, ultrasound at 20 weeks indicated a female fetus. The investigators stressed that direct evidence of a vanishing twin was not provided, but the possibility was raised. They noted that vanishing twins can be detected early in the pregnancy, although they realize that procedures for doing so are not always possible. An alternative plan would be to develop a specific, definitive marker for identifying female fetuses who are presently detected by the absence of a Y chromosome.

\section{Transfusion Syndrome Markers}

Twin-to-twin transfusion syndrome is a serious prenatal condition, affecting a subset of monochorionic-dichorionic MZ twins. This condition involves the unequal blood flow from one twin (donor) to the other (recipient), leading to within-pair discrepancies in size and in health. The donor is typically smaller in size and often has anemia, while the recipient is typically larger and may experience cardiac failure due to increased blood volume (MedlinePlus, 2014). As the investigators of a new study point out, unequal blood flow via fetal anastomoses affects all monochrionic-dichorionic twin pairs, but the more serious transfusion syndrome affects only $15 \%$ of such pairs (Miura et al., 2014).

Miura et al. (2014) conducted some early studies showing that increased levels of cell-free $h P l \mathrm{mRNA}$ in maternal circulation predicted twin-to-twin transfusion. However, the sample size was too small to allow firm conclusions. Therefore, they attempted a subsequent study using nine mRNAs, mostly placental. Their analysis included data from 28 pregnant women seen at 12-21 weeks gestation at the Obstetrics Clinic of Nagasaki University Hospital, in Japan. Transfusion syndrome was not detected in any of the participants at the time of the study, although it was later detected in 11 women. A control group comprised of women pregnant with non-twins showed no pregnancy complications.

Six of the nine mRNAs were predictive of transfusion syndrome, providing a non-invasive means for detection of the condition. However, the source of these mRNAs and the events regulating them remain uncertain. A large-scale prospective study is needed for further evaluation of the findings.

\section{MZ Twin Discordance for Wilson's Disease}

MZ twin pairs discordant for medical conditions offer critical cues to the onset and expression of diseases in nontwins. A case report of two sets of MZ twins, discordant for Wilson's disease is of interest (Czlonkowska et al., 2009). Wilson's disease is an autosomal recessive condition marked by abnormal functioning of the copper-transporting protein adenosine triphosphate 7B. This disruption leads to accumulations of copper in the liver and brain. Wilson's disease is linked to mutations in the gene $A T P 7 B$, located on chromosome 13. 
The twins in question were both female. The first pair was studied at 38 years of age. One co-twin experienced mild jaundice at age $7-10$ years, but appeared healthy until age 35 . She began to experience fatigue, jaundice, hemolysis, liver function decompensation and depression. In contrast, her co-twin exhibited no symptoms of Wilson's disease, but showed decreased copper serum ceruloplasmin and serum copper, and tested positive for anti-Hepatitis B and antiHepatitis Bc antibodies in serum. The second pair of twins, also female, was studied at age 28 years. One co-twin was diagnosed with lung pneumonia at age 21 , followed by thrombocytopenia (low platelet count). Beginning at age 26 , she variously experienced headaches, dizziness, unstable gait, and loss of balance. Subsequent symptoms included liver abnormalities and abnormal copper metabolism. Her twin sister had irregular menses and abnormal nose bleeding. She experienced no neurological difficulties, but among her symptoms were increased bilirubin, decreased leukocyte count and thrombocytopenia. Her test results for antiHepatitis B and anti-Heptatis Bc antibodies were negative.

The investigators speculated that clinical differences between the genetically identical co-twins most likely reflected epigenetic differences. This is important, given that it has been previously believed that allelic heterogeneity is primarily responsible for variations in Wilson's disease. It was also noted that epigenetic differences tend to be greater between older twins and twins who spend relatively little time together. However, the twins in question had been raised together and had similar lifestyles, suggesting that unspecified internal factors might explain their disease differences. It should be noted, however, that living together or apart may not be associated with all observed differences between MZ twins - personality similarity is the same for MZ twins, regardless of rearing status (Tellegen et al., 1988).

\section{Media}

\section{Big at Birth}

Approximately $50 \%$ of twins weigh less than 2,500 grams (5 pounds, 5.18 ounces) at birth (Blondel \& Kaminski, 2002). Therefore, the birth weights of male twins, Jack and Robbie, of 9 pounds, 10 ounces and 9 pounds, 3 ounces, respectively, are newsworthy (Wilkinson, 2014). The twins were born on August 20, 2014 at the Women's Hospital at Saddleback Memorial Medical Center, in Laguna Hills, California. Their combined weight of 18 pounds, 13 ounces distinguishes them as the largest set of twins born at that hospital. However, in 2008 opposite-sex twins with a combined weight of 23 pounds, 1 ounce were born in Winston-Salem, North Carolina (Associated Press, 2008). Interestingly, the female twin (12 pounds, 3 ounces) outweighed her male co-twin (10 pounds, 14 ounces) by 1 pound, 5 ounces.

\section{Planned Separation of Conjoined Twins}

Conjoined female twins were detected in the pregnancy of a Texas mother at 19 weeks gestation (Talarico, 2014). The twins, born at 31 weeks, share a liver, diaphragm, pericardium (heart lining) and intestines, as well as some lung tissue. Surgeons believe the twins can be separated easily, although the surgery still poses a small risk of death to one or both twins. The operation will take place when the twins are 6-8 months of age, possibly in mid to late fall 2014. Meanwhile, tissue expanders will be used to obtain additional skin that the twins will require during surgery.

\section{Factor Twins}

Kyle and Josh Brooks are identical twins from Cardiff, Wales who are making their way through the $\mathrm{X}$ Factor competition on their shared singing talent (Walesonline, 2014). The twins have been singing together, mostly at church, since they were small. It was there that they learned how to play guitar and drums, but they never took formal singing lessons. The twins, who are just 15 years old, perform under the stage name 'The Brooks'.

It is interesting to speculate on how successful one twin would have been without the other. Perhaps, the opportunities to practice together and/or the visual interest that singing twins attract partly explain their popularity. However, see the fictional and true stories told in cinema, The Identical, below.

Cinema: the identical. The 2014 film, The Identical, is set during the Depression in the rural south. It tells the story of identical male twins, Dexter and Ryan, separated at birth because their biological parents could not afford to raise two children. The decision to relinquish one infant son for adoption was made when the twins' father encountered an evangelical preacher whose wife could not bear children; the twins' father saw this meeting as an opportunity to help a couple raise a family and to provide his son with a better life.

In the film, both twins display extraordinary musical talent as children. The twin raised by his biological parents (Dexter) eventually becomes a star and bears an unmistakable resemblance to the late Elvis Presley. (Elvis Presley had a twin brother, Jessie Garon, who was stillborn.) In contrast, his twin brother Ryan's musical career is derailed by his father, who envisions his son in the ministry. Ryan eventually follows his musical dreams, but can only become 
'The Identical' stand-in for his famous co-twin. The twins never meet and the events that follow are best learned from seeing the film itself.

The actual story of Elvis Presley and the fictional story of Dexter and Ryan diverge, but Presley's life history was surely the inspiration for this film. Here, too, it is worth wondering if Elvis Presley's twin would have had the same musical talent as the living twin and, if so, how that would have affected Presley's career. Such issues are of great interest to twin researchers who will find The Identical worth seeing for that reason.

\section{References}

Associated Press. (2008, June 20). Oh baby! Newborn twins tip scales at 23 pounds. Retrieved from http://www.nbcnews. com/id/25288150/ns/health-womens health/t/oh-babynewborn-twins-tip-scales-pounds/\#.VAn7ohaAHwI

Blondel, B., \& Kaminski, M. (2002). Trends in the occurrence, determinants, and consequences of multiple births. Seminars in Perinatology, 26, 239-249.

Czlonkowska, A., Gromadzka, G., \& Chabik, G. (2009). Monozygotic female twins discordant for phenotype of Wilson's disease. Movement Disorders, 24, 1066-1069.

Kaplan, R. (2008, July 21). College choice is twin dilemma. USA Today. Retrieved from http://usatoday30.usatoday. com/news/education/2008-07-20-college-twins'N.htm

Lopes, A. A., Tani, G., Katzmarzk, P. T., Thomis, M. A., \& Maia, J. A. (2014). Association between birth weight and neuromotor performance: A twin study. Scandinavian Journal of Medicine and Science in Sports, 24, e140-e147.

Lyons, D. M. (2014). The twin parent's guide to college admissions. Retrieved from http://twiniversity.com/2014/05/ the-twin-parents-guide-to-college-admissions/
MedlinePlus. (2014, August 15). Twin-to-twin transfusion syndrome. Retrieved from http://www.nlm.nih.gov/ medlineplus/ency/article/001595.htm

Miura, K., Higashijima, A., Miura, S., Mishima, H., Yamaskaki, K., Abe, S., ... Masuzaki, H. (2014). Predominantly placenta expressed mRNAs in maternal plasma as predictive markers for twin-twin transfusion syndrome. Prenatal $\mathrm{Di}$ agnosis, 34, 345-349.

Mosle, S. (2008, July 27). Is there a better half? New York Times. Retrieved from http://www.nytimes.com/2008/07/27/ education/edlife/27twins.html?pagewanted $=$ all\& $r=0$

Rubenstone, S. (2014). Elite-college admission for twins. College Confidential. Retrieved from http://www.college confidential.com/dean/000266/

Talarico, L. (2014). Hope, faith strong for conjoined twins at Texas Children's Hospital. Retrieved from http://www.wfaa. com/story/news/local/texas-news/2014/09/03/hope-faithconjoined-twins-texas-childrens-hospital/15008341/

Tellegen, A., Lykken, D. T., Bouchard, T. J., Jr., Wilcox, K. J., Segal, N. L., \& Rich, S. (1988). Personality similarity in twins reared apart and together. Journal of Personality and Social Psychology, 54, 1031-1039.

Vlková, B., \& Hodosy, J. (2014). Vanishing twin as a potential source of bias in non-invasive fetal sex determination: A case report. Obstetrics and Gynaecology Research, 40, 11281131.

Walesonline. (2014, September 7). X Factor 2014: Identical twins Kyle and Josh Brooks from Cardiff storm their audition. Retrieved from http://www.walesonline.co.uk/ whats-on/whats-on-news/x-factor-2014-identical-twins7731395

Wilkinson, J. (2014, August 27). Supersize delivery. Orange County Register, 1, 15. 